\title{
The Mechanism for Implementing the Sector Model of Functional Zoning
}

\author{
Denis Denisov $^{1, *}$, Tatyana Zhuravleva², Mikhail Zhuravlev ${ }^{3}$ \\ ${ }^{1}$ Department of Foreign Languages, Samara State Transport University, Samara, Russia \\ ${ }^{2}$ Department of Architectural and Construction Graphics and Fine Arts, Samara State Technical University, Samara, \\ Russia \\ ${ }^{3}$ Department of Architecture, Samara State Technical University, Samara, Russia \\ Corresponding author. Email: denisansk@gmail.com
}

\begin{abstract}
The sector model of functional zoning was identified in 2016 on the basis of an analysis of the distribution of facilities in St. Petersburg, Samara (Russia) and refined on the basis of a sectoral administrative-territorial division scheme adopted in Minsk (Belarus) and Moscow (Russia) (2020). This study explains the mechanism of differentiated distribution of objects that is found in different cities and at different scales from the estate planning to the level of geopolitics. This step is necessary to integrate the sector model of functional zoning into the theoretical apparatus of modern architecture. In animals, this mechanism is defined as magnetic sensation. The implementation of the "magnetic feeling" in human activities for the development of the space of a large city has its own specifics, taking into account both natural-scientific factors, and issues of perception and cognitive processes. In world practice, this description is undertaken for the first time. As the first factor of the "structuring effect" of a certain central object (area, green zone, water body) on the surrounding buildings, the authors accept the natural-scientific factor of gravity. The authors adhere to the point of view that a certain symbolic meaning, which is somehow fixed in culture, arises with respect to the degree of illumination, position in the sky, and the direction of movement of the Sun. These values arise on the basis of the relative positions of the analyzed territory, planet Earth and the Sun. The second factor is the person's ability to perceive these influences and the intuitive ability to correlate them, as well as the purpose of the placed objects with the types of activities identified in philosophy and determined by the daily cycle. The result of the joint action of these two abilities is the assignment of certain objects with a greater degree of probability to certain sectors. The need to take into account two additional administrativeterritorial units (central, as well as placed outside the sector model) determines the transition from a purely sector model to an integer ten-element functional topological model. In this regard, the development of a sector model of functional zoning is accompanied by an appeal to ten-element models of a generalized description of extremely complex processes that are found in antiquity similarly to the sources of the sector model of functional zoning.
\end{abstract}

Keywords: functional zoning, urban planning, magnetic alignment, Vastu Vidya, tetractys

\section{INTRODUCTION}

The factor of cardinal points is taken into account in modern urban planning when compiling a wind rose, i.e. when identifying prevailing or seasonal air currents in the analyzed region, and as a factor in the illumination of objects and specialized premises. For example, when placing sports stadiums, the orientation of their longitudinal axis along $\mathrm{N}-\mathrm{S}$ even prevails over the convenience of placement relative to the surrounding landscape.
In ancient times, the factor of cardinal points could have absolute significance. The status of the northern and eastern parts of the world was especially distinguished. So, the residence of the military leader in the Roman army was in the northern part of the military camp. Later, the main planning axis of the Roman cities was cardo, a road oriented from south to north. In sacred architecture, for example in Christianity, this opposition is realized in placing the entrance in the western, and the altar in the eastern sectors. If the monarch wanted to show himself as the ruler of spiritual life in his kingdom, for example, in the castle of Chambord (Château de Chambord, France), then the monarch (in this case, Francis I) lodged in the premises of 
the eastern wing, and the chapel, on the contrary, was transferred in the castle of Chambord to the west wing.

In ancient and medieval periods, much attention was paid to the central zone (the "sacred square") of both the estates and the monastery ensembles of Southeast Asia and Southern Europe. Residential and utility rooms were located along its perimeter. The central space under the dome of the cathedral or circus also has a special status. The function of conditionally void space in the architecture of modern buildings is implemented in atriums (open space inside a building that combines two or more floors, as a rule, with a light lamp), but in this application the main function becomes the aesthetic one. Architectural ensembles can act in the development of megacities as "central" territories; for example, the Moscow Kremlin in relation to the Central Borough of Moscow and, accordingly, the Central Borough of Moscow in relation to Moscow as a whole. Natural formations can act in geopolitics as significant "conditionally empty" zones; for example, the Gulf of Finland in relation to the cities located along its perimeter: to Helsinki, St. Petersburg, Tallinn. Functional zoning in this article means such a distribution of functions in space that distinguishes zones of anthropogenic landscape with a pronounced direction of use. Function is a process taking place in a given space and its role relative to other processes. A number of publications by a team of coauthors consisting of D.V. Denisov, M.Yu. Zhuravlev, N.Yu. Medvedeva, T.D. Zhuravleva develops a functional topological model of landmark object zoning in large cities based on material from St. Petersburg and Samara [1-3]. The functional topological model with reference to the sectoral pattern of the administrative-territorial division of the cities of Moscow (for the period from 1990 to 2012) and Minsk was named the "sector model of functional zoning" according to its most representative part $[4,5]$. The following factors are considered as factors that influenced the development of the functional topological model: a) archaic ideas of the cardinal points taken into account when planning and placing buildings [6-8]; b) modern geopolitical spatial oppositions; c) the data of zoopsychology about the preferences of some animals in relation to cardinal points $[9$, 10]; d) an impartial attitude towards the research results that do not fit into the modern picture of the world, both classical and postclassical. Sources that were taken into account when creating this model belong to the most diverse fields of knowledge. Consideration of factors providing a mechanism for the distribution of the functions of landmark objects across sectors, regardless of the size of the analyzed central zone and its "sphere of influence", is required for the full inclusion of the sector model of functional zoning in architecture theory.

Within the framework of the sector model, self-organization processes are implemented in a functional specification of each sector (district in the city Minsk and borough in the city of Moscow) in a clockwise direction, starting from the northern sector. This one is accepted, on the one hand, as a resting point, on the other hand, as a synthetic element, containing all potency. The presentation of the results of the study in the third part of the article will be undertaken precisely from the north. A natural-scientific prerequisite for considering this cycle of selforganization, in which, due to the natural mechanisms, each sector of a large city begins to solve special tasks intended only for it, is the allocation of daylight in physics as a synthetic element and seven prismatic colors as its components.

In contrast to the eight-element sector zoning model, the functional topological model is ten-element and has a reference point in the northwestern sector. For example, the Central district in Minsk, which is historically the first one and has the first serial number, is located in the northwestern sector (Fig. 1). All nine districts in Minsk (Belarus) are located sectorally.

Doubling in the ten-element model of the functions assigned to the Northwest (stages I, IX) and the North (II, X), on the one hand, structurally establishes the continuity of one cycle with respect to the other. On the other hand, this opens up the possibility of taking into account the central zone and the object located outside. So, the Central Borough (No. 1) is additionally distinguished in Moscow (Russia), which coincides with the geometric center, and the Zelenograd Borough (No. 10), which was part of the city during the analyzed period, but located outside the Moscow Ring Road (Fig. 2). The Soviet (northern) district on the map of the administrative-territorial division of the city of Minsk and the Northern Borough in Moscow receive a second serial number.
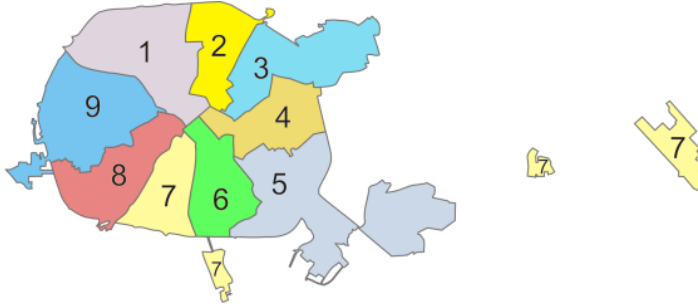

Figure 1 Administrative division of Minsk [11]

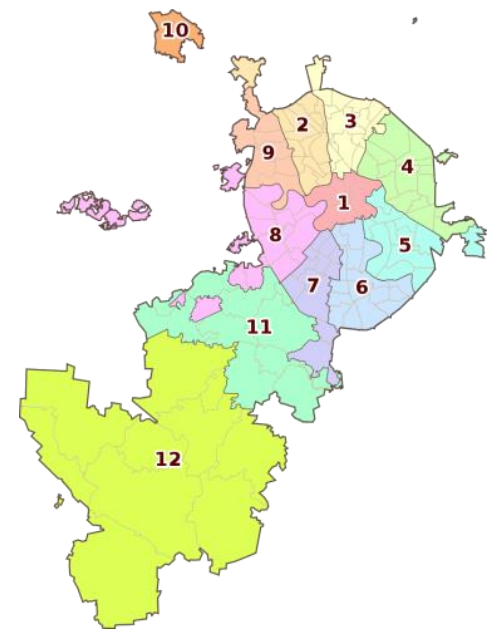

Figure 2 Administrative division of Moscow [11]

The transition from a purely spatial definition of sectors within the framework of a functional topological model to integer modeling makes it possible to take into account the functional identity of each element of the model under constantly changing conditions [12]. So, nine districts of Samara (Russia), located at the arrow of the Samarka and Volga rivers, reflecting the stages of historical development, follow from the confluence of rivers in the northeast direction. But an appeal to a numerical modification of the functional topological model reveals general principles with the sector model of the development of territorial-administrative units in this case [1]. 


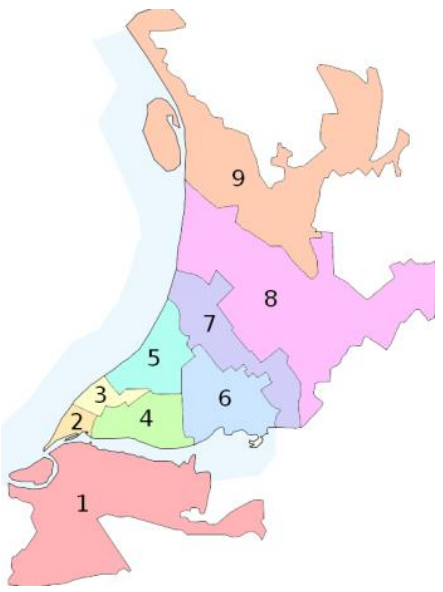

Figure 3 Administrative division of Samara [11] with original color correction

In this regard, the development of a sector model of functional zoning is accompanied by an appeal to ten-element models of a generalized description of extremely complex processes that are found in antiquity as well as the origins of the sector model of functional zoning.

\section{METHODOLOGY}

The appeal to the factor providing the mechanism of the sector model of functional zoning is tantamount to modeling the process of a structural influence on the functional development of the territory adjacent to a certain spatial object occupying a central position. The authors believe that the factor of the structuring influence on the distribution of landmark objects across eight sectors of space should satisfy two requirements: 1) the nature that allows its perception at an elementary (physiological and / or intuitive) level; 2) the ability to maintain stable internal relationships in the context of constantly changing landscapes, forms, natural-scientific and sociohistorical factors. An example of the relationship between constantly changing shapes of objects and stability is mathematical topology, which studies the properties of figures (spaces) that are preserved under continuous deformations.

The authors offer an interconnected explanation of two factors applicable to the zoning of any territory, regardless of its size and location: a) solar gravity as a natural-scientific factor; b) a cognitive matrix as a factor reflecting the specifics of being a rational person and as a tool for generalizing the types of activities determined by the daily cycle [13]. The extent to which the potentials of the central spatial object as a space "structuring the surrounding development" are developed or not depends on other factors determining the prospects of the territory as a whole with respect to the natural, urban landscape, the existing transport infrastructure, and relevant socio-historical processes.

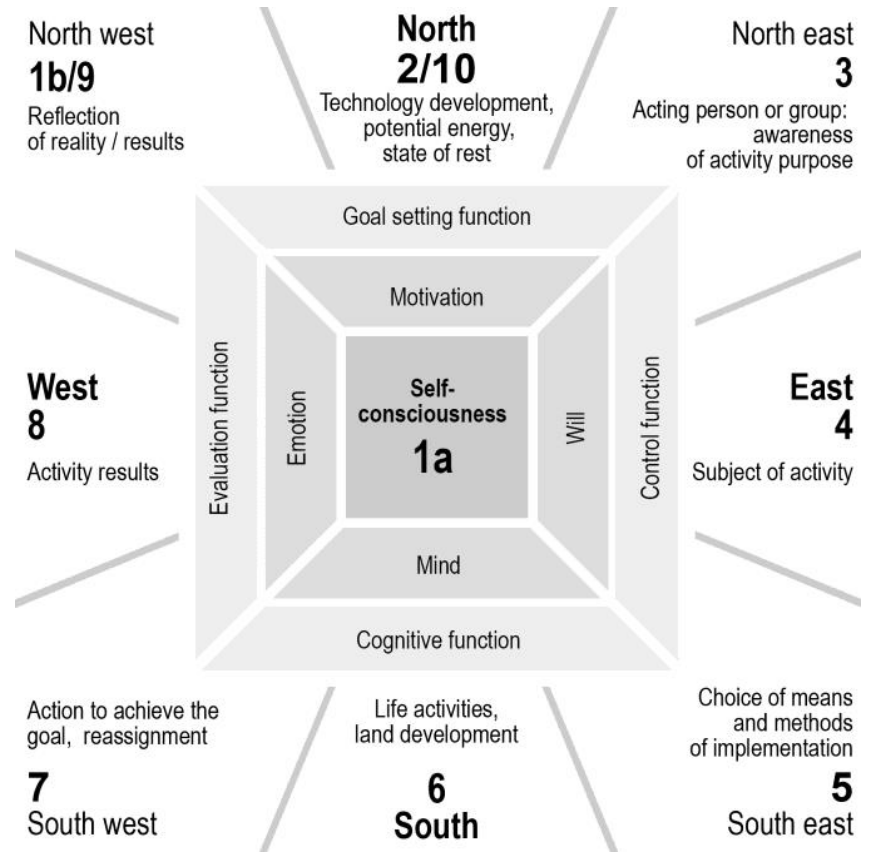

Figure 4 Functions of consciousness and activities in relation to the daily cycle [13]

The third factor is the ability to form semantic oppositions by any two objects located on a certain territory; it is not considered in this article. Their interconnected being means that they will interact not at the level of their own ontologies, but at the level of inclusion in human being. According to psychology, a special psychic reality arises in each interaction of two subjects, for example, two people, a person and a pet, a person and his house plant. The interaction of these two objects in the functional topological model is mediated by human perception.

A well-known physical experiment with a magnet and its effect on metal shavings could be an illustration of the structuring potential of the central area of a particular spatial object, assuming that the source of the structuring effect is in its central space. Due to the low probability of detecting such a significant structural potential in a limited space, the authors attempt to find such a source outside and consider as such the gravitational effect produced by the Sun. Accordingly, the objective of this study is to establish correlations between the position of the Sun in the sky (sector, angular position, direction of movement) with the functions of the sector zoning model and corresponding types of human activity.

The idea of the cognitive matrix as the driving force of selforganization processes that facilitate the ordering of objects within the framework of the sector model of functional zoning was proposed by D.V. Denisov in the monographic study "Numerical models of the universe: an approximation to Sankhya" in 2013 [13]. For these purposes, a combination of the consciousness structure was undertaken, including the main components (intelligence, emotions, motivation, will) and the correlating functions (cognitive, evaluative, goal-setting, controlling) with the structure of activity [14]. In such an application, there is no particular novelty for the humanities, including cultural studies. The concept of "mental map" is well known. The scientists talk about the mental map of Russian space [15], about the anthropology of space [16], about regional ontologies [17]. The novelty lies in the application of the cognitive matrix (mental map with emphasis on cognitive processes) to functional zoning. 
The cognitive matrix of 2013 for the most part entered the functional topological model unchanged. The names of individual activities have been clarified in Fig. 4 and in Table 1. Numbering from 1 to 10 both in the figure and in the table indicates the phase integration of three levels of organization and, accordingly, three matrices (each of them is eight-element) into a single model. Elements 1-8 belong to the level of selfawareness, elements 2-9 correspond to the natural level, which is correlated with the sector model, and elements 3-10 correspond to the level of realization of an individual's cognitive abilities.

The peculiarity of this matrix is the correlation of sectors and corresponding elements (numbers from 1 to 10) with ten elements of the Pythagorean tetractys [10], the attributes of which are included in column 2 of table No. 1. These attributes, but not the method of structuring in the form of a pyramid ("1", "2-3", "4-5-6", "7-8-9-10"), illustrating the principle of hierarchy of being and giving this model a name, are significant for the upcoming analysis. Thus, the attributes of the Monad "the basis of constancy", "pure light, commanding everyone", "synthesis of all numbers" are relevant in the case of the Central Borough of Moscow at number 1 (Fig. 2). These attributes could be interpreted in a similar way with respect to the central district of each capital. The authors of the study regard the tetractys model as a tool for a generalized description of highly complex processes developed in antiquity in the absence of probabilistic methods of analysis.

The transformation of the three-part model (in our application, the center, the middle, and the intermediary element that communicates with the periphery) into the 10-element model in the Sankhya model of being, which has a total of 25 elements, is more significant for the present study. It is the oldest of the six Indian philosophical systems, known as the philosophy of numbers. The Sankhya model is dual, it includes the spiritual principle "Consciousness" (Purusha, el. 25; acc. Monada) and the plastic material principle "Uncreated Nature" (Prakriti, el. 24; acc. Duade), eight-element structure which (el. from 24 to 17) is comparable with eight sectors of the considered sector model. This model becomes ten-element in Sankhya thanks to

\section{Table 1 Ten element basis of sector model of functional zoning}

\begin{tabular}{|c|c|c|c|}
\hline Cardinal points & $\begin{array}{c}\text { The structure of } \\
\text { activities based on [13] } \\
\text { (compare with Fig. 4) }\end{array}$ & $\begin{array}{c}\text { Pythagorean tetractis } \\
\text { elements and their } \\
\text { attributes [13] }\end{array}$ & $\begin{array}{c}\text { General characteristics and urban } \\
\text { development functions of eight sectors } \\
\text { of the functional topological model [1] }\end{array}$ \\
\hline Northwest & $\begin{array}{c}\text { Reflection of reality } \\
\text { (projection from the } \\
\text { reality of self- } \\
\text { consciousness, spirit) }\end{array}$ & $\begin{array}{c}\text { I. Monad: the basis of } \\
\text { constancy; pure light } \\
\text { commanding all; synthesis } \\
\text { of all numbers }\end{array}$ & $\begin{array}{c}\text { In Fig. 1 the goal-setting function } \\
\text { corresponds to the central element "Self- } \\
\text { awareness" (1a) or its projection onto the } \\
\text { North }\end{array}$ \\
$\begin{array}{c}\text { Point of rest, potential } \\
\text { energy, source of all } \\
\text { phenomena; technology } \\
\text { development }\end{array}$ & $\begin{array}{c}\text { II. Duad: the foundation of } \\
\text { plurality }\end{array}$ & $\begin{array}{r}\text { 2. The state of rest: conservation objects, } \\
\text { potential energy, natural potencies; } \\
\text { technology development }\end{array}$ \\
\hline Northeast & $\begin{array}{c}\text { Subject of action (or } \\
\text { group): awareness of the } \\
\text { purpose of the activity }\end{array}$ & $\begin{array}{c}\text { III. Triad: piety, mind, } \\
\text { friendship, harmony, peace, } \\
\text { unanimity }\end{array}$ & $\begin{array}{c}\text { 3. Impulse, prayer, perception of the idea } \\
\text { by the knowing subject, primacy in the } \\
\text { functional structure of development, transit }\end{array}$ \\
\hline
\end{tabular}

the "Mind" element (manas, el. 16; corresponding to Decade), which cognizes the upper 9 elements, leads and directs the group of 16 lower elements [13]. Regarding this element, Zelenograd (part of the city of Moscow from 11/25/1968) receives a functional justification as "City of Science" and "Soviet Silicon Valley". The city of Zelenograd was conceived as a satellite city of Moscow and a garden city, but it was reoriented to the development of electronics and microelectronics (significant elements of any control system) as part of the creation of a comprehensive center for microelectronics "Scientific Center" even before the start of construction work. The comparison shows that the functions of cognition and control, fixed in the Sankhya for the 10th ordinal number (the 16th ordinal element in the original ascending ontological order) coincide with the expressed direction of development of Zelenograd.

The central element of "Self-Consciousness" (el. 1a) of the cognitive matrix (Fig. 4) can be projected, within the framework of the sector model, into the northwestern sector. On the one hand, the "Reflection of Reality" function of this sector is realized in the ideal sense as goal-setting. On the other hand, this function means reflection and summarizing all contradictory results obtained in the western sector (el. 8).

The function of the quiescent point, potential energy, and the source of all phenomena is assigned to the northern sector in the cognitive matrix. This function is also updated twice. The goal formulated in the central area or the northwestern sector (el. 1a / 1b) is entrusted in the northern sector to the natural development cycle, which the sector model is considered in this study (el. 29). All the results of this development are stored in the northwestern sector (el. 9) of the cognitive matrix. In parallel, the development of the cognitive subject originates in the northeastern sector (el. 3), which ends in the northern sector (el. 10) by gaining the ability to master potentialities of Nature (see above about el. "Mind"). This means that at first Nature becomes the executor of a certain plan, possibly even divine, then, in turn, the person who has formed the necessary skills becomes the executor of this plan. 


\begin{tabular}{|c|c|c|c|}
\hline & & & function, broadcast centers \\
\hline East & Subject of activity & $\begin{array}{l}\text { IV. Tetrad: the number of } \\
\text { the world, elements of } \\
\text { nature, seasons... }\end{array}$ & $\begin{array}{l}\text { 4. The metropolitan function and related } \\
\text { functions of determining the direction of } \\
\text { development and its cardinal change, the } \\
\text { placement of worship structures, the } \\
\text { implementation of the spectacular function } \\
\text { and the gardening function }\end{array}$ \\
\hline Southeast & $\begin{array}{l}\text { The choice of means and } \\
\text { methods of } \\
\text { implementation }\end{array}$ & $\begin{array}{l}\text { V. Pentade: midpoint, } \\
\text { equilibrium, justice }\end{array}$ & $\begin{array}{l}\text { 5. Prosperity, identity, self-sufficiency, } \\
\text { fuels and lubricants, that is, the availability } \\
\text { of means and methods of implementation }\end{array}$ \\
\hline South & $\begin{array}{c}\text { Life activities, space } \\
\text { development }\end{array}$ & $\begin{array}{l}\text { VI. Hexada: a number that } \\
\text { animates, harmonizes the } \\
\text { world, supports the health of } \\
\text { creatures, eradicates disorder } \\
\text { and chaos, an authoritarian } \\
\text { and creative force that forces } \\
\text { matter to orderly changes }\end{array}$ & $\begin{array}{l}\text { 6. The sphere of residence and life, } \\
\text { including power, achievements for the } \\
\text { benefit of the people and raising the level } \\
\text { of culture, resolution of contradictions, } \\
\text { prevention of health as well as dying; } \\
\text { short-term intensive business processes }\end{array}$ \\
\hline Southwest & $\begin{array}{l}\text { Actions to achieve the } \\
\text { goal, reassignment }\end{array}$ & $\begin{array}{l}\text { VII. Heptad: Acropolis, a } \\
\text { "strong fortress" within a } \\
\text { decade, but it has no extent - } \\
\text { a critical moment, case }\end{array}$ & $\begin{array}{l}\text { 7. Actions to achieve the result: seizure of } \\
\text { the initiative, intervention or the opposite - } \\
\text { establishing the state power, defense } \\
\text { production, large technological complexes }\end{array}$ \\
\hline West & Activity results & $\begin{array}{l}\text { VIII. Ogdoad: friendship, } \\
\text { love, wisdom, creative } \\
\text { thoughts }\end{array}$ & $\begin{array}{l}\text { 8. Inconsistency: traditional education, } \\
\text { humanistic values, on the one hand, and } \\
\text { the desire for leadership (leadership as an } \\
\text { end in itself), the primacy of capital, on the } \\
\text { other hand. Placement of structures } \\
\text { demonstrating military prowess, financial } \\
\text { institutions, authorities reflecting capitalist } \\
\text { tendencies, water-related facilities }\end{array}$ \\
\hline Northwest & $\begin{array}{l}\text { Reflection of reality } \\
\text { (totality or review of all } \\
\text { the results obtained, both } \\
\text { positive and negative; } \\
\text { see paragraph Northwest } \\
\text { above) }\end{array}$ & $\begin{array}{l}\text { IX. Ennead: unity, lack of } \\
\text { dispute, limitation }\end{array}$ & $\begin{array}{l}\text { 9. The completion of the production cycle, } \\
\text { the placement of the results of activities in } \\
\text { warehouses, overcoming the vices, } \\
\text { diseases, wear and tear that arose in the } \\
\text { course of activities. Overcoming the } \\
\text { limitations of current activities. Active } \\
\text { confrontation in politics and in sports of } \\
\text { high achievements }\end{array}$ \\
\hline North & $\begin{array}{c}\text { Technology } \\
\text { development; see } \\
\text { paragraph North above) }\end{array}$ & $\begin{array}{l}\text { X. Decade: (all) } \\
\text { containment, fate, power }\end{array}$ & $\begin{array}{l}\text { 10. The mind mastering the potencies of } \\
\text { Nature }\end{array}$ \\
\hline
\end{tabular}




\section{RESULTS}

\subsection{North}

The rotation of the Earth around the Sun seems to be insignificant for the sectoral zoning of a certain territory. The factor of relative position of the Sun (a), the analyzed object (b) and the planet Earth (c) is to consider. It is enough to characterize the two extreme points for the initial consideration of this factor: the position of the Sun at its zenith and nadir. These provisions create effects that can be given the status of functions. So, the position of the Sun on the other side of the globe, corresponding to the northern sector, expresses the idea (function) of potentiality. The proposed solution implies the physiological ability of a person, like any other creature of an animal or plant, as well as the ability of inorganic matter to perceive gravitational influences and respond to them. The corresponding urban development conservation function assigned to the northern sector can be implemented in the placement of such objects as depots, garages, warehouses, tombs (but not cemeteries), museums, power plants, raw materials processing enterprises and high-tech enterprises. An example is the location of the Peter and Paul Fortress in St. Petersburg north of the Winter Palace. This fortress did never fight (function "state of the rest"), it contains the royal tomb, as well as the mint (function of potentiality). Today, a large shopping and entertainment center in a modern urban space can act as an object that consolidates a maximum of potential opportunities.

Table No. 1 makes it possible to translate individual antique attributes of the numbers in the Pythagoras tetractis into the language of functions. So, the concept of potentiality assigned to the North in the functional topological model of zoning corresponds, on the one hand, to the Duad attribute "foundation of plurality", and, on the other hand, to the Decade's attributes "(all) containment", "fate", and "power". The Decade's attribute "(all) containment" reflects the breadth of the range of cognitive activity, and the attribute "power" indicates a management function. The concept of "North" in the framework of the functional topological model combines the aspects of "potentials" and "natural resources" with the ability to develop them, which significantly expands the set of objects that can be found in the northern sector. We give as a good example the location of Paris, the capital of France and a center with a powerful "cultural irradiation", which researchers define as "eccentric" [16].

The location of the Olimpiysky sports complex in the Meshchansky (northern) district of the Central Borough of Moscow can be explained on the basis of the A.P. Lyusy's concept of northern cultures. The scientist characterizes northern cultures as a whole as creative, generating new ideas, opening up new worlds. In our case, the consolidation of a brotherly attitude to man for the northern cultures is significant. The 1980 Olympics was held in an acute confrontation with the United States. Therefore, the placement of the Olimpiysky sports complex in the northern sector, which forms a rest point and, accordingly, a zone of peace in the cycle under consideration, seems natural from the point of view of the functional topological model. This point of view is supported by the name of the Prospekt Mira (the PeaceProspekt) passing nearby.

\subsection{South}

The concept of the intensity of sunlight can lead in the case of all other sectors except the northern one. The position of the Sun at the highest point in the sky is associated with its maximum degree. On the one hand, light is a necessary component of all life processes and activities, on the other hand, the maximum illumination depresses life processes. Accordingly, the South combines two opposite trends: the maintenance of life processes and their cessation. This point of view can be found is in cultural studies, too. In the ancient Indian picture of the world, South is the kingdom of mortals, where the god of the kingdom of death, Yama, the very first of mortals, rules. Modern scholars incorrectly interpret this space as the kingdom of the dead. In cultural studies, the South is a side of the world in which the tendency toward material production is correlated with an exploitative attitude toward man, and, accordingly, eschatological teachings arise that treat the end of the world [17]. The functional topological model in this sector intensively implements both the function of residential development and the placement of cemeteries. Administrative, cultural objects that reflect the trend of "everything for the good of the people" can be located in the southern sector (for example, railway stations in the 19th century). The placement of technological facilities in the southern sector is effective, according to the functional topological model, only subject to regular maintenance activities. In the functional topological model, the southern sector of the residential function correlates with the attribute of the Hexad "number that animates, harmonizes the world, and maintains the health of beings". Its attribute "authoritarian and creative power that forces matter into orderly changes" refers to upbringing and education. The Southern Borough in Moscow is the most populated, while the Leninsky district (South-South-East) in Minsk accounts the most number of government agencies. The President's residence, 9 ministries, the Constitutional court, the Supreme economic court, the CIS Executive Committee, and foreign embassies are located there. In the neighboring Oktyabrsky (South-South-West) is located the Minsk railway station.

The functional certainty of the remaining sectors arises with respect to two distinguished vectors: 1) from pure potentiality to development for sectors from northeast to southeast; 2) from maximum activity to net potentiality for sectors from southwest to northwest. 
Accordingly, the middle position of the Sun in the sky between nadir and zenith will be common for the eastern and western sectors. The direction of their movement is different: ascending in the case of the East and descending in the case of the West. The question arises about the interpretation of this parameter. The general solution in the framework of this study is that any object located in the cardinal sectors acquires, on the basis of correlation with the phases of the movement of the Sun in the sky, additional symbolic meaning: potentiality - for the North, prospects and leadership - for the East, efficiency and short duration - for the South, the inconsistency, depending on the disclosure of all potentials, both positive and negative, and an extreme desire for leadership - for the West. Further, due to the powerful gravitational force of the luminary, the symbolic meanings acquire the status of real functions within the framework of the sector zoning model.

\subsection{East}

East is characterized in a functional topological model based on a functional reading of the ancient Indian mythology about the existence of deities. Five of the following functions were revealed: a) the altar side of the world (in which the deities live); b) the function of managing global processes (similar to how deities control the elements and pacify them); c) recreational function (deities are believed to live among trees in parks and groves); d) the function of heroism (selected hero kings visit them); e) the entertainment function (deities, unlike people, do not suffer, but are in constant contemplation, listen to heavenly singers and watch dances of heavenly dancers) [1]. The following buildings in St. Petersburg are located east of the river Neva's section between the Peter and Paul Fortress and the Winter Palace, taken as a reference point: Summer Garden (functions a, c, e), Champ de Mars (function d), Smolny Palace, which became the headquarters of the Bolsheviks in 1917-1918 (function b). Comparison with the attributes of the Tetrad "the number of the world, elements of nature, seasons" of the Pythagorean tetractis makes it possible to draw attention to the function of managing global processes (b).

\subsection{West}

The West is a side of the world in which both positive and negative trends are realized equally, which cannot but lead to contradictions, since negative trends are always more dynamic. A functional reading of the ancient Indian mythology associated with the West as a party of demons allows you to pay attention to the power and belligerence characteristic of these mythical creatures. Placement of financial, commercial institutions, administrative governing bodies and the implementation of the function of demonstrating military prowess can be expected in urban areas. Western European scholarship (the function "the best traditions in education") in this context acts as a factor secondary to the function of militancy and enhancing its potential [1]. The Ogdoad's attributes "friendship", "love", "wisdom", "creative thoughts" in relation to the sector zoning model emphasize humanistic tendencies (the first two attributes) and the classical scientific tradition (the last two attributes) cultivated in Western Europe, while the general background of European and especially American politics determines the desire for primacy in all areas of life.

\subsection{Northeast}

In the framework of the proposed approach, the intermediate sides can be characterized in relation to the previous element (sector) by the definition of "updated". So, the characteristic of the northern sector is "potentiality", and the Northeast is "actualized potentiality". The attributes of the Triad "piety", "mind", "friendship", "harmony", "peace", "unanimity" can be used to interpret it. According to the work "Vedic architecture of Vastu: Principles of building our ideal home", which reflects the current trends in Vastuvidya, the most important area responsible for the sustainable development of the analyzed object is Northeast. It offers places of solitude and prayer, and relatively void objects, such as parking lots (in the northern and eastern sectors). The function of the Northeast is transmitted by the image of the rising sun, symbolizing technological progress (the function of scientific knowledge), spiritual growth, longevity and health. Continent Africa, in which the relevant sector is "cut off", is cited as a negative example; the Japanese islands and Lake Baikal, elongated in the northeast direction, are cited as positive examples [18]. The Pervomaisky (northeast) district (No. 3) of Minsk, in which the Academy of Sciences of Belarus is located, can be cited as a positive example. Elk Island National Park occupies the northeastern sector in Moscow, that is, the basic condition guaranteeing success and prosperity has been met. However, due to the administrative-territorial subordination of the national park to the Eastern Borough (No. 4), a certain shift arose in the northwestern and northern sectors and the North-Eastern Borough (No. 3) turned out to be north of the Central Borough (No. 1).

The function of the subject of knowledge in the urban landscape is fixed in the form of landmark objects associated with the personality of the founder, for example, the House of Peter I in St. Petersburg in the northeast of the indicated reference point. The function of the subject of knowledge and the primary object in the structure of functional development in Moscow is symbolized by the sculptural composition of Vera Mukhina "Worker and Kolkhoz Woman" (1937; height $24.5 \mathrm{~m}$ ), standing on the roof of the museum and exhibition center of the same name (height $34.5 \mathrm{~m}$ ), which is part of VDNH complex (North-Eastern Borough). The maximum manifestation of water expected in Vastuvidya in the northeastern sector 
[18] takes the form of the Rostokinsky aqueduct in Moscow.

The primacy of the northeast sector in Moscow can be seen in the fact that the first radial metro line in Russia (1937) passed through the territory of the Krasnoselsky (northeast) district of the Central Borough. The specifics of the northeastern sector as a transit sector marking the transition from night to day (i.e., from one system to another) is also expressed in the location of large transport facilities. In Moscow, which has a lot of railway terminals, Komsomolskaya Square is located in the North-Eastern Borough, known as the "square of three terminals"; so, Finland Station (terminal) in St. Petersburg [1].

\subsection{Southeast}

The geographical concept of "Southeast" often implies such concepts as "identity", "fertility", "earthly wealth", "prosperity", "independence". The last of them can manifest itself as a function of "lagging or exclusion from actual political and economic processes" in certain periods of history. This applies equally to the states of Southeast Asia, Southeast Ukraine, Kurds (Southeast Turkey), Moscow (Southeast in relation to St. Petersburg). The specificity of the southeastern regions in tetractis is marked by such attributes of the Pentade as "justice" and "equilibrium point". In urban space, alleys with flowers and fountains, or boardwalks with many shops can become symbols of prosperity. An example of such a promenade is Nevsky Prospekt in St. Petersburg. There is also the Moscow station (terminal in St. Pertersburg), which performs a transport function, as well as the northeastern sector of the functional topological model.

\subsection{Southwest}

The beginning of the downward movement of the luminary can serve as a symbol of the weakening of certain positions, the reassignment and redistribution of power. This is, in fact, a continuation of the topic of inequality and exploitation, relevant to the southern sector. Significant at this stage are also the processes of opposing these trends to assert sovereignty. For example, the placement of shipyards in St. Petersburg, providing protection of maritime borders, falls on the northwestern sector. In the same meaning, this sector is characterized by the attributes of the Heptade: "strong fortress within a decade", "critical moment, chance".

\subsection{Northwest}

The final stage of the downward movement of the luminary in the northwestern sector symbolizes the actualization of contradictory trends assigned to the western sector. Contradictions accumulate in the western sector. The most dynamic of them lead to consolidation processes in the northwestern sector. An example of consolidation with a northwestern accent is North Atlantic Treaty Organasition. At this stage, we can talk about both high achievement sports and preventive measures. In St. Petersburg, the first is represented by sports complexes, the second by ship-repair factories (as applied to workers, placing of medical institutions is expected). Products at this stage of the activity cycle are prepared for shipment or sent to a warehouse. The Ennead's attribute "restriction" indicates the end of the activity cycle, and the attributes "unity", "lack of dispute" draw attention to the processes of consolidation and a sense of teamwork, which is important in some sports.

\section{DISCUSSION}

Presentation of data on the functional distribution of objects in large cities of Russia and the capital of Belarus served as an illustration of the mechanism of functional zoning, which operates with equal efficiency at all levels of spatial organization. The influence of solar gravity on the functional specification of individual sectors of space can be said if the planet Earth is considered as a separate object, constantly located below the analyzed territory, and the Sun acts as a dynamic center of gravity. In detail, the functional topological model is influenced by five factors. The first two of them are solar gravity (a) and the intensity of sunlight (b). The third one is human ability to perceive changes in the position of this center of mass in the sky, both at the physiological level (for example, with the help of the cerebellum) and in the visual range (c). The fourth factor consists in a person's ability to intuitively correlate activities with the daily cycle and space sectors as well as make up consepts of the unique specifics of a particular space sector (d). These four factors are decisive in the development of territories and the distribution of functional objects. The fifth factor is again the gravity factor in combination with the intensity of sunlight (e), which is designed to confirm or reject decisions made by a person on the functional application of the placed objects. Decisive for this confirmation is the routine factor of daily repetition of the same position of the Sun in the sky above this object. If functions of each sector are codified in the city-planning, the position of the Sun at a certain time over the analyzed object can be considered as a factor that actualizes certain functions.

This article covers many disciplines with its subject matter. The debatability of this work is obviously associated with a discussion between different branches of science.

For architects, including co-authors of this study, the concept of the participation of solar gravity is not about physical gravity, but about a metaphor, about the "psychological sensation of some spatial dominants". However, agreement is observed (including with colleagues from Belarus) on the existence of uniform principles of organization for all eight sectors in all cities 
analyzed, since we are talking about factual material collected in the framework of applied functional, namely functional topological analysis.

The present study and functional topological analysis as a whole for philosophers is "an entertaining, we can say eccentric, idea of applying the ancient Indian philosophy of number to the most diverse facts of life and culture in their spatial manifestations" [19]. Hundreds of ancient and modern models analyzed within functional topological approach, including activity cycles (from creation myths to robotics or conveyor production), functional zoning in the ancient world (Greece, India, China, Rome, Russia), in modern architecture, as well as the composition of paintings are transformed "into a game of beads" and "mysticism of numbers" in the philosopher's perception. The prejudice is such that the philosopher is not even able to recognize that the functional basis of the space sectors in the sector model of functional zoning is the structure of activity given in a philosophical interpretation [14]. The possibility of implementing topological functions in accordance with the functional topological model in a particular city is not allowed by modern philosophers. The reviewer refers to the philosophical authorities: "It is obvious that they would be greatly puzzled by thoughts about the 'function of primacy' and its implementation in that event", when a monument to the founder of the city was erected in the corresponding sector of the square [19]. It can be seen from the foregoing that the discussion of the functional topological model is just beginning. Is it problematic and controversial that a sector model of functional zoning is possible? Do these factors make up its mechanism? The problem and controversy is also not that in China's Feng Shui and Indian Vastu-Vidye, the factor of cardinal points has been successfully used for thousands of years to this day and is also taken into account by large international companies. The problem with the perception of the functional topological model is that it states that specialists and ordinary people who decide on the location of the smallest and largest objects in Russia and Europe, i.e. far from the indicated ancient traditions, make their decisions on an intuitive level within the framework of the functional topological model, which, like these ancient eastern traditions, has its roots in the mythological picture of the world.

Obviously, the discussion on the topic of the functional topological model cannot yet take place. Therefore, we conclude the discussion by pointing out the proximity of the functional topological model, eight sectors of which serve as a clear illustration of the process of selforganization, the concept of J. Forrester, a developer of the theory of system dynamics, who believed that megalopolises are more characteristic of self-organization than management [20].

\section{CONCLUSION}

The scientific novelty of this study is the transfer of concepts from the field of the humanities, cultural studies and philosophy to the field of the theory of urban planning and territorial planning. The viability of this approach is confirmed by the analysis of large anthropogenic objects of various origin and historical development, such as Moscow, Minsk, St. Petersburg and a number of more local territorial objects. In the analyzed examples (cases), the natural distribution of functions and the imposition of certain meanings on individual large architectural objects in the vast majority is carried out according to the proposed scheme. The functional topological model combines: a) a cognitive matrix that includes the types of activities adopted in philosophy, regarding which the primary endowment of space sectors with unique functions takes place; b) sector model of functional zoning; c) a numerical model to expand the scope of the sector model.

\section{REFERENCES}

[1] Origins as a factor in the organization and development of space: genesis, number, topology, probability, classification, D.V.Denisov (Rd.), SamGUPS Press, 2016.

[2] D.V. Denisov, M.Yu. Zhuravlev., N.Yu. Medvedeva, Functional and topological model of space development: on the example of the Glory Square of Samara, Samara Conurbation and the historical part of St. Petersburg, Postgraduate Bulletin of the Volga Region 7-8 (2015) 34-40.

[3] D.V. Denisov, M.Yu. Zhuravlev, N.Yu. Medvedeva, A.S. Khokhrin, Komsomolskaya Square of Samara as a subject of functional topological analysis, Urban planning and architecture 4 (2018) $67-$ 73.

[4] D.V. Denisov, M.Yu. Zhuravlev, N.Yu. Medvedeva, I.I. Malkov, Functional aspects of intracity municipality sectoral zoning of Minsk, Urban planning and architecture 1 (2020) 92-100. DOI:

10.17673/Vestnik.2020.01.13

[5] D. Denisov, T. Zhuravleva, M. Zhuravlev, E. Kabanova, Function-topological model of urban space sectoral zoning, in: E3S Web of Conferences, 2020, vol. $164,04016$.

[6] E.V. Tyulina, The temple, the World, the Text: Vastuvidya in the Tradition of the Puranas, East literature Press, 2010. 
[7] N.G. Nesterenko, The construction ritual in ancient India, in: History of world culture: traditions, innovations, contacts, Moscow University Press, 1990, pp. 13-23.

[8] S.M. Neopolitanskij, S.A. Matveev, Sacred architecture of the world, in: Creative principles of world harmony, Amrita Press, 2013.

[9] J. Broschart Der gepolte Fuchs, GEO 3 (2011) 136.

[10] S. Begall, J. Červeny, Ju. Neef, O. Vojtěch, H. Burda, Magnetic alignment in grazing and resting cattle and deer, in: Proceedings of the National Academy of Sciences, 2008, September 9, vol. 105, No. 36, pp. 13451-13455. DOI:

https://doi.org/10.1073/pnas.0803650105

[11] Wikipedia, The free Encyclopedia, Available at: https://www.wikipedia.org/.

[12] N.M. Latypova, D.V. Denisov, Philosophy of number and probabilistic model of the distribution of university premises: on the example of SSTU, in: Science and Culture of Russia, XIIth International scientific-practical conference, Samara, SamGUPS Press, 2016, pp. 78-83.

[13] D.V. Denisov, Numbers and Ontological Modeling: towards the method of Sankhya, SSTU Press, 2013.

[14] V. Il'in, A. Mashencev, Philosophy in diagrams and comments, Piter Press, 2008.

[15] V.I. Spiridonova, Russian space. New dating experience, Philosophical sciences 8 (2012) 19-30.

[16] T.Ju. Zagrjazkina, Anthropology of space: on French-language material, Philosophical sciences 4 (2012) 9-28.

[17] A.A. Lyusy, Global landmarks and regional ontologies of culture. North-South: Russian and world, Philosophical sciences 10 (2008) 75-85.

[18] K. Shastri, Vedic architecture of Vastu: Principles of building our ideal home, Philosophical book, 2012.

[19] N.F. Zyuzev, Review on the monograph: The First Principles as Factors of Territory Development and Formation, Man, culture, education: scientific, educational and methodological journal 4(30) (2018) 230-234.
[20] J.W. Forrester, Urban Dynamics, M.I.T. Press, 1969. 